\title{
Helicobacter pylori Antibiotic Resistance: What is the Future of Treatment?
}

\author{
Mohammad Zamani, ${ }^{1,}$ Vahid Zamani, ${ }^{2}$ and Javad Shokri-Shirvani ${ }^{3}$ \\ ${ }^{1}$ Student Research Committee, Babol University of Medical Sciences, Babol, IR Iran \\ ${ }^{2}$ Vice-Chancellery for Health, Babol University of Medical Sciences, Babol, IR Iran \\ ${ }^{3}$ Department of Internal Medicine, Rohani Hospital, Babol University of Medical Sciences, Babol, IR Iran \\ "Corresponding author: Mohammad Zamani, Student Research Committee, Babol University of Medical Sciences, Babol, IR Iran. Tel: +98-9359493131, E-mail: \\ mzamani20@gmail.com
}

Received 2016 January 09; Revised 2016 February 11; Accepted 2016 March 06.

Keywords: Antibiotics, Resistance, Treatment, Helicobacter pylori

\section{Dear Editor,}

In a recent issue of Iranian journal of Pediatrics, we read with great interest the study by Maleknejad et al. in which they determined the susceptibility of Helicobacter pylori strains isolated from infected children in north Iran, to some antibiotics, such as clarithromycin, amoxicillin, and tetracycline (1).

Although the sensitivity of $H$. pylori to many antibiotics has been confirmed in vitro, its eradication is not easy in vivo. The standard triple therapy consists of a proton pump inhibitor (PPI) and two antibiotics, such as clarithromycin, metronidazole, and/or amoxicillin, for 7 - 14 days. However, the rate of eradication is lower than $80 \%$ (2). The main cause of the eradication failure is related to $H$. $p y$ lori resistance to the antibiotics. Also, surveys indicate that the prevalence of antibiotic resistance is variable among countries, and this can change within the same country (3). Results showed that the resistance to clarithromycin can occur through repeated use of this drug for respiratory infections and point mutations in the 23S rRNA gene of $H$. pylori. Also, resistance to metronidazole is probably related to inactivation of $r d x A$ (which encodes an oxygeninsensitive NADPH nitroreductase), $f d x B$ (ferrodoxin-like protein), and frxA(NADPH flavin oxidoreductase) genes (4). Additionally, H. pylori resistance to amoxicillin can be explained by alternations in penicillin-binding proteins (5).

Recent studies have investigated new alternatives to existing treatment approaches. For example, quadruple regimens containing a PPI plus clarithromycin, amoxicillin, and metronidazole have been shown to be more effective than standard triple therapy (6). Also, bismuth quadruple therapy has been reported to be more successful in areas with rates of clarithromycin resistance above $15-20 \%$, and if not accessible, non-bismuth quadruple, both sequentially and concomitantly, can be used (7). Fur- thermore, it has been suggested that azithromycin can be used instead of clarithromycin to treat children in standard triple therapy within a shorter period (8). This substitution can also decrease concerns about resistance to clarithromycin as a result of its widespread use. In addition, some studies have stated that specific probiotics, such as Streptococcus boulardii and Lactobacilli johnsonii, can reduce the load of $H$. pylori and increase its eradication rate, especially among children (9). Moreover, different experimental studies reveal that several bioactive compounds from medicinal plants (e.g., flavonoids, saponins, and quinons) have gastroprotective and anti-H. pylori activity (10). This demonstrates that herbal medicine can potentially provide a source of therapeutic agents against $H$. pylori infection.

Although classic triple therapy is still the preferred first line regimen for eradication of $H$. pylori infection, its efficacy has been seriously challenged. In addition, it seems that patterns of antimicrobial resistance are diverse in different regions. On the other hand, not enough studies have confirmed alternative strategies to current treatment methods, particularly for children. Therefore, it is necessary for more research be conducted to find new and suitable therapy regimens with high efficacy and fewer side effects for the eradication of $H$. pylori infection, considering the geographic patterns of antibiotic resistance. Greater recognition of genotypic resistance patterns of $H$. pylori to antibiotics will also help us in this regard.

\section{References}

1. Maleknejad S, Mojtahedi A, Safaei-Asl A, Taghavi Z, Kazemnejad E. Primary Antibiotic Resistance to Helicobacter pylori Strains Isolated From Children in Northern Iran: A Single Center Study. Iran J Pediatr. 2015;25(6):2661. doi:10.5812/ijp.2661. [PubMed: 26635938].

2. Horvath A, Dziechciarz P, Szajewska H. Meta-analysis: sequential therapy for Helicobacter pylori eradication in children. Aliment Pharmacol 
Ther. 2012;36(6):534-41. doi: 10.1111/j.1365-2036.2012.05229.x. [PubMed: 22827718].

3. Seo JH, Jun JS, Yeom JS, Park JS, Youn HS, Ko GH, et al. Changing pattern of antibiotic resistance of Helicobacter pylori in children during 20 years in Jinju, South Korea. Pediatr Int. 2013;55(3):332-6. doi: 10.1111/ped.12048. [PubMed: 23279258].

4. Khademi F, Faghri J, Poursina F, Esfahani BN, Moghim S, Fazeli $\mathrm{H}$, et al. Resistance pattern of Helicobacter pylori strains to clarithromycin, metronidazole, and amoxicillin in Isfahan, Iran.J Res Med Sci. 2013;18(12):1056-60. [PubMed: 24523796].

5. Ogata SK, Godoy AP, da Silva Patricio FR, Kawakami E. High Helicobacter pylori resistance to metronidazole and clarithromycin in Brazilian children and adolescents. J Pediatr Gastroenterol Nutr. 2013;56(6):645-8. doi: 10.1097/MPG.0b013e31828b3669. [PubMed: 23403439].

6. Malfertheiner P, Megraud F, O'Morain CA, Atherton J, Axon AT, Bazzoli F, et al. Management of Helicobacter pylori infection-the Maastricht IV/ Florence Consensus Report. Gut. 2012;61(5):646-64. doi: 10.1136/gutjnl-2012-302084. [PubMed: 22491499].

7. Molina-Infante J, Romano M, Fernandez-Bermejo M, Federico A, Gravina AG, Pozzati L, et al. Optimized nonbismuth quadruple therapies cure most patients with Helicobacter pylori infection in populations with high rates of antibiotic resistance. Gastroenterology. 2013;145(1):121-128 e1. doi: 10.1053/j.gastro.2013.03.050. [PubMed: 23562754].

8. Esmaeili-Dooki MR, Shirdel H, Hajiahmadi M. Eradication of Helicobacter pylori in Children by Triple Therapy Regimens of Amoxicillin, Omeprazole, and Clarithromycin or Azithromycin. Iran J Pediatr. 2015;25(6):2360. [PubMed: 26635936].

9. Pacifico L, Osborn JF, Bonci E, Romaggioli S, Baldini R, Chiesa C. Probiotics for the treatment of Helicobacter pylori infection in children. World J Gastroenterol. 2014;20(3):673-83. doi: 10.3748/wjg.v20.i3.673. [PubMed: 24574741].

10. Awaad AS, El-Meligy RM, Soliman GA. Natural products in treatment of ulcerative colitis and peptic ulcer.J Saudi Chem Soc. 2013;17(1):10124 